\title{
COBERTURAS DO SOLO E CRESCIMENTO DA MACIEIRA NA IMPLANTAÇÃO DE UM POMAR EM SISTEMA ORGÂNICO DE PRODUÇÃO'
}

\author{
TÂNIA REGINA PELIZZA², ÁLVARO LUIZ MAFRA, \\ CASSANDRO VIDAL TALAMINI DO AMARANTE ${ }^{4}$, , MARCOS ANDRÉ NOHATTO5, \\ LEANDRO VARGAS 6
}

RESUMO - O uso de coberturas é uma estratégia de manejo do solo que pode influenciar no desenvolvimento de plantas de espécies frutíferas. O objetivo deste trabalho foi avaliar o crescimento da macieira, na fase de implantação de um pomar, em resposta ao uso de diferentes materiais e plantas de cobertura de solo. O pomar foi implantado em 2003, em Vacaria-RS, com a cv. Galaxy, sendo conduzido no sistema de produção orgânico. O delineamento experimental foi em blocos ao acaso, com três repetições, envolvendo os seguintes tratamentos nas linhas de plantio: testemunha (sem manejo da cobertura do solo), capina, plástico preto, sombrite, serragem de pínus, acícula de pínus, palha de capim-rabo-de-burro, azevém, aveia-preta, aveiapreta + ervilhaca, aveia-preta + nabo-forrageiro, azevém + trevo-branco + espécies espontâneas e roçada. A cobertura do solo por plantas espontâneas foi avaliada mensalmente no período de primavera-verão, durante dois anos, sendo relacionada com o desenvolvimento da macieira. Os tratamentos capina, plástico preto, acícula de pínus e palha de capim-rabo-de-burro mantiveram a cobertura do solo por plantas espontâneas inferior a $20 \%$. A altura e o diâmetro das plantas de macieira diminuíram à medida que aumentou a cobertura do solo por plantas espontâneas, evidenciando competição entre ambas.

Termos para indexação: Malus domestica Borkh., manejo do solo, plantas de cobertura do solo.

\section{SOIL COVERAGE AND APPLE TREE GROWTH ON THE ESTABLISHMENT OF AN ORCHARD UNDER ORGANIC PRODUCTION SYSTEM}

\begin{abstract}
Soil cover is one of the options for weed management in the orchard but this might affect fruit trees development. The objective of this work was to evaluate apple trees growth during the orchard establishment stage by using different materials and soil cover plants. The experimental apple orchard was planted in 2003, in Vacaria, RS, Southern of Brazil, with the cv. Galaxy managed under organic system. The experiment followed the randomized block design, with three replications. The treatments were applied in the tree rows, as follows: control (without weed management), manual weeding, black plastic film, black net, pinus sawdust, pinus needle mulch, Andropogon sp mulch, annual ryegrass (Lolium multiflorum), black oat (Avena strigosa), black oat + common vetch (Vicia sativa), black oat + fodder radish (Raphanus sativus), annual ryegrass + white clover (Trifolium repens) + spontaneous plant cover, weed mowing. The soil covered by weeds was monthly measured, during the spring/summer season, over the second and third years of the orchard establishment, and this was related to the apple trees growth. The treatments with manual weeding, black plastic film, pinus needle and Andropogon mulch maintained the soil cover by weeds below $20 \%$. The apple tree height and diameter decreased with the increase of soil cover by weeds, reflecting weeds competition with apple trees.
\end{abstract}

Index terms: Malus domestica Borkh., soil management, soil covering plants.

\footnotetext{
'(Trabalho 225-08). Recebido em: 29-08-2008. Aceito para publicação em: 04-05-2009.Parte do trabalho de Dissertação de Mestrado em Produção Vegetal do primeiro autor, desenvolvido junto ao Centro de Ciências Agroveterinárias (CAV) da Universidade do Estado de Santa Catarina (UDESC), em Lages-SC.

${ }^{2}$ Engo Agro, M.Sc., Doutoranda em Fruticultura de Clima Temperado. Bolsista do CNPq. Universidade Federal de Pelotas - UFPEL/ FAEM. Caixa Postal 354, CEP 96010-900, Pelotas-RS. E-mail: trpelizza@gmail.com

${ }^{3}$ Engo Agro, Dr., Professor do Departamento de Solos e Recursos Naturais, CAV/UDESC, CEP 88520-000, Lages-SC. E-mail: a2alm@cav.udesc.br

${ }^{4}$ Engo Agro, PhD., Professor do Departamento de Agronomia, CAV/UDESC, Lages-SC. Bolsista de Produtividade em Pesquisa do CNPq. E-mail: amarante@cav.udesc.br

${ }^{5}$ Engo Agro, Mestrando em Fitossanidade, UFPEL/FAEM, Pelotas-RS.

${ }^{6}$ Engo Agro, Dr., Pesquisador da Empresa Brasileira de Pesquisa Agropecuária (EMBRAPA), Centro Nacional de Pesquisa do Trigo, (CNPT), Rodovia BR 285, km 294, Passo Fundo-RS.
} 


\section{INTRODUÇÃO}

O uso de coberturas é uma das principais formas de manejo do solo em pomares, podendo ser utilizadas espécies vegetais de rápido crescimento para produção de fitomassa, ou outros materiais, tais como plástico preto, sombrite, serragem e acícula de pínus. O manejo adequado da cobertura pode proporcionar melhoria de atributos físicos, químicos e biológicos do solo (Medeiros, 1992; Neves et al., 2006), o que auxilia na produção das fruteiras (Ragozo et al., 2006), merecendo especial atenção em sistemas de produção orgânica (Walsh et al., 1996; Goh et al., 2000).

Dal Bó \& Becker (1994) reportaram aumento na produtividade em videiras com o uso de plantas de cobertura de inverno, em relação à capina de plantas espontâneas, possivelmente por melhorias promovidas no solo. Todavia, o cultivo de leguminosas em pomares de ameixeira, na região montanhosa da Índia, resultou em frutos maiores e mais pesados, porém com decréscimo na produtividade, quando comparado ao tratamento dessecado quimicamente, no sexto ano de avaliação (Shylla \& Chauhan, 2004). Mais recentemente, verificou-se que o uso de plantas de cobertura de inverno, com exceção do nabo forrageiro, incrementou o desenvolvimento das plantas de pessegueiro, em pomar na região de Morro Redondo-RS, avaliado até o segundo ano de implantação (Rufato et al., 2007).

O manejo cultural representa alternativa ao controle químico de plantas espontâneas, sendo utilizado comumente em áreas de produção frutífera, com possíveis benefícios em termos de redução nos custos e melhoria dos recursos naturais, ao manter a cobertura do solo (Carvalho \& Vargas, 2004). Por outro lado, pouco se conhece acerca dos efeitos do manejo da cobertura do solo sobre a ocorrência de plantas espontâneas e sua competição com plantas de macieira nas condições do Sul do Brasil, sobretudo na produção orgânica, em que as estratégias culturais têm especial interesse. O papel da cobertura do solo, em termos de supressão da vegetação espontânea, depende do estabelecimento inicial das plantas de cobertura, da densidade populacional e dos resíduos produzidos (Carvalho \& Vargas, 2004). Uma alternativa para impedir o crescimento das plantas espontâneas é a colocação de plástico preto, muito utilizado na cultura do morangueiro (Medeiros \& Santos, 2003). A capina é outra forma de controle de plantas espontâneas, mas requer muita mão de obra e deixa o solo descoberto, sujeito à erosão. Além disso, a ação mecânica da capina pode danificar o sistema radical da macieira. Entre as práticas de manejo das plantas de cobertura do solo mais utilizadas em pomares, destaca-se a roçada, que controla o desenvolvimento das plantas espontâneas e deixa uma camada vegetal protegendo o solo (Matheis et al., 2006).

O objetivo deste estudo foi avaliar o crescimento de plantas de macieiras a partir da fase de implantação de um pomar, em resposta à utilização de diferentes coberturas do solo para manejo das plantas espontâneas presentes na linha de plantio.

\section{MATERIAL E MÉTODOS}

O experimento foi conduzido na Embrapa Uva e Vinho/Estação Experimental de Fruticultura Temperada, em Vacaria-RS, em um Latossolo Bruno, durante os ciclos de produção de 2004/2005 e 2005/2006. O clima da região ("Cfb" segundo classificação de Köeppen) é mesotérmico úmido, com verões amenos e precipitação bem distribuída ao longo do ano (Moreno, 1961). O pomar de macieira foi implantado em 2003, sendo utilizada a cultivar Galaxy, sobre porta-enxerto Marubakaido, com filtro M9. Foi utilizado o espaçamento de 1,5 x 5,0 m, e as plantas, conduzidas com líder central.

O delineamento experimental foi em blocos ao acaso, com três repetições, cada uma constituída de cinco plantas. Os tratamentos consistiram na testemunha (sem manejo da cobertura do solo), capina manual, roçada, plástico preto, sombrite (com $70 \%$ de sombreamento), serragem nova de pínus, acícula de pínus, palha de capim-rabo-de-burro (Andropogon sp.), mais as coberturas de aveia-preta (Avena strigosa), azevém (Lolium multiflorum), aveia-preta + ervilhaca (Vicia sativa), aveia-preta + nabo-forrageiro (Raphanus sativus) e azevém + trevo-branco (Trifolium repens) + espécies espontâneas. Os tratamentos foram instalados na linha de plantas, numa faixa de $1 \mathrm{~m}$ de largura. $\mathrm{O}$ plástico preto e o sombrite foram fixados nas laterais com uma camada de solo e arame. As coberturas mortas de serragem, acícula e palha foram aplicadas em outubro, com uma camada de $10 \mathrm{~cm}$ de espessura sobre o solo. Em todos os tratamentos onde foi utilizado "mulching", a cobertura foi reposta anualmente no início de cada ciclo de produção. As plantas de cobertura foram semeadas a lanço, em abril de 2004 e 2005 , nas faixas de cultivo, com as seguintes densidades: $50 \mathrm{~kg} \mathrm{ha}^{-1}$ para aveia-preta; $70 \mathrm{~kg} \mathrm{ha}^{-1}$ para ervilhaca; $20 \mathrm{~kg} \mathrm{ha}^{-1}$ para nabo; e $20 \mathrm{~kg} \mathrm{ha}^{-1}$ para azevém. Nos consórcios, estas quantidades foram reduzidas pela metade. O manejo das plantas de cobertura do solo, nos respectivos tratamentos, foi feito com uma roçada no mês de setembro. O tratamento com roçada foi conduzido com roçadeira manual, efetuando-se as 
operações a $10 \mathrm{~cm}$ de altura do solo, durante todo o ano, quando a vegetação atingiu $40 \mathrm{~cm}$ de altura. As capinas foram realizadas manualmente a cada 30 dias. Quando da instalação das coberturas vegetais, o solo encontrava-se limpo. Foram efetuadas capinas antes da instalação de cada um dos tratamentos a fim de uniformizar cada um deles.

Os dados climatológicos, durante a execução do trabalho, foram coletados no posto meteorológico localizado na Estação Experimental da Embrapa, em Vacaria-RS. A precipitação média no período de abril a setembro de 2004 foi de $111 \mathrm{~mm}$, enquanto para o mesmo período de 2005 foi de $456 \mathrm{~mm}$. Durante o ano de 2004, a precipitação média anual foi de 1.249 $\mathrm{mm}$ e no ano de 2005 foi de $2.152 \mathrm{~mm}$. Durante o ano de 2005, a média da temperatura mínima foi de $10,8^{\circ} \mathrm{C}$ enquanto a máxima foi de $21,2^{\circ} \mathrm{C}$. Em 2004, a média da mínima foi de $9,7^{\circ} \mathrm{C}$ e a média da máxima foi de $21,3^{\circ} \mathrm{C}$. Para os períodos compreendendo abril a setembro de 2004, a média da temperatura mínima foi de $8,3^{\circ} \mathrm{C}$, e a máxima, de $18,1^{\circ} \mathrm{C}$, enquanto para o mesmo período de 2005 , foram de $7,6^{\circ} \mathrm{C}$ e $18,9^{\circ} \mathrm{C}$, respectivamente. $\mathrm{O}$ manejo do pomar seguiu os procedimentos preconizados para o sistema orgânico (Brasil, 1999), sendo utilizados calda bordalesa, calda sulfocálcica e óleo de neem como tratamentos fitossanitários. Nas entrelinhas do pomar, a única operação realizada foi a roçada mecanizada para manejo das plantas espontâneas, com frequência de acordo com a necessidade. A calagem e a adubação foram realizadas conforme recomendações da Comissão de Química e Fertilidade do Solo (CQFS-RS/SC, 2004), com base em análise de solo, sendo utilizados calcário dolomítico, fosfato natural e adubos orgânicos.

A cobertura de solo pelas plantas espontâneas foi avaliada mensalmente, de outubro a fevereiro, nos ciclos de 2004/2005 e 2005/2006, por observação visual, quantificando-se a percentagem de solo coberto, considerando-se $100 \%$ no tratamento-testemunha e $0 \%$ nos tratamentos capina e plástico preto. A taxa de decomposição das plantas de cobertura do solo foi avaliada pela perda de massa em amostras do material acondicionadas em sacos de tule de $0,25 \mathrm{~m}^{2}$, dispostos sobre a superfície do solo. Efetuaram-se avaliações mensais, a partir de setembro de 2005 até janeiro de 2006, pesando-se as amostras em balança digital. Ao final de cada avaliação, as amostras foram recolocadas sobre a superfície de cada tratamento. $\mathrm{O}$ crescimento das plantas de macieira foi avaliado em fevereiro de 2005 e de 2006, medindo-se a altura das plantas desde a superfície do solo até a extremidade do ramo mais alto e o diâmetro do tronco, tomado 10 $\mathrm{cm}$ acima do porta-enxerto, sendo medidas as duas plantas por repetição.
Os resultados foram submetidos à análise de variância e teste de comparação de médias (teste de Duncan; $P<0,05)$. A cobertura do solo pelas plantas espontâneas foi relacionada com a altura e o diâmetro do tronco das macieiras, adotando-se modelo linear de regressão. Para velocidade de decréscimo da biomassa seca das plantas de cobertura, em função do tempo de manejo, foram ajustados modelos de regressão linear ou hiperbólico, adotando-se para cada cobertura o modelo com maior coeficiente de determinação e nível de significância.

\section{RESULTADOS E DISCUSSÃO}

As principais plantas espontâneas que ocorreram na área do experimento, durante o período de avaliação, foram língua-de-vaca (Rumex obtusifolius), picão-preto (Bidens pilosa), almeirão-docampo (Hypochoeris brasiliensis), losna-do-campo (Ambrosia elatior), tansagem (Plantago tomentosa), dente-de-leão (Taraxacum officinale), aveia-louca (Bromus catharticus), capim-lanudo (Holcus lanatus) e milhã (Digitaria horizontalis). A ocorrência de plantas espontâneas variou entre os tratamentos nos dois períodos de crescimento da macieira. No período de 2004/2005, os diferentes materiais e os manejos na linha de plantio mantiveram a percentagem de solo coberto com plantas espontâneas inferior a $40 \%$ (Figura 1). O uso do sombrite, neste período, favoreceu o desenvolvimento de guanxuma (Sida rhombifolia), especialmente no período de dezembro a fevereiro. Nos ciclos de 2004/2005 e 2005/2006, o tratamento com acícula de pínus foi o mais eficiente, resultando, na $2^{\mathrm{a}}$ época, em menos de $25 \%$ de cobertura do solo pelas plantas espontâneas, seguido dos tratamentos com serragem, sombrite e palha de capim-rabo-de-burro (Figura 1). Acreditase que o baixo percentual de plantas espontâneas no tratamento com acícula de pínus se deve aos efeitos fitotóxicos da mesma. Segundo Almeida (1991), mesmo depois de mortas, as plantas mantêm as substâncias alelopáticas em seus tecidos e, quando liberadas, podem inibir a germinação e o desenvolvimento inicial. Da mesma forma, a decomposição de materiais deixados sobre a superfície do solo é mais lenta do que em materiais incorporados, o que faz com que a liberação de aleloquímicos seja mais lenta, perdurando por mais tempo. Outro fator a ser considerado é o de que a serrapilheira de coníferas produz efeito acidificante sobre as camadas superficiais do solo (Williams \& Gray, 1977), o que poderia contribuir por limitar a presença de algumas plantas mais bem adaptadas a maiores valores de $\mathrm{pH}$.

A eficiência no uso de coberturas mortas 
no manejo de plantas espontâneas, em pomar de macieira pode ser verificada em resultados obtidos por Shribbs \& Skroch (1986) que avaliaram diferentes espécies de gramíneas (Triticum aestivum, Muhlenbergia shreberi, Poa pratensis, Dactylis glomerata, Festuca arundinaceum) e leguminosas (Rubus laciniatus, Lespedeza stipulaciea, Rumex acetosella, Ambrosia artimesifolia, Trifolium subterraneum) como materiais de cobertura, além de solo nu e cobertura morta composta por palhada de Secale cereale. Neste trabalho, melhores resultados quanto ao diâmetro do tronco das plantas e comprimento de brotações foram obtidos com o uso de cobertura morta ("mulching") de Secale cereale.

As plantas de cobertura de inverno mostraram variações quanto ao controle da vegetação espontânea. $\mathrm{O}$ azevém e a aveia-preta suprimiram em mais de $75 \%$ o estabelecimento de plantas espontâneas no ciclo de 2004/2005 (Figura 1). No entanto, no ciclo de 2005/2006, o controle foi menor, em torno de $15 \%$ na média das avaliações. Essa redução pode ser atribuída à estiagem ocorrida no ciclo de 2004/2005, fazendo com que as plantas de cobertura apresentassem menor crescimento e baixa produção de biomassa seca.

No ciclo de 2005/2006, o acúmulo de biomassa seca pelas plantas de cobertura variou de $0,26 \mathrm{~kg} \mathrm{~m}^{-2}$ na cobertura com aveia-preta, a 0,50 $\mathrm{kg} \mathrm{m}^{-2}$ para o azevém + trevo- branco + espécies espontâneas (Figura 2).

Em relação à decomposição da palha, houve variação entre as espécies em termos de perda de biomassa no período avaliado (Figura 2), sendo o decréscimo linear nas duas gramíneas em cultivo solteiro, e hiperbólico nos consórcios de espécies. Uma das práticas utilizadas para aumentar a cobertura do solo é o cultivo consorciado, que pode produzir maior biomassa seca em relação aos cultivos solteiros (Balbinot Júnior et al., 2003). Tal efeito manifestou-se para os cultivos consorciados de aveia-preta e azevém, em relação aos cultivos solteiros destas gramíneas. Ressalta-se que a quantidade de biomassa produzida pelas plantas de cobertura é um dos principais fatores que contribui para o controle de plantas espontâneas (Erasmo et al., 2004), interferindo tanto nas plantas em desenvolvimento, como sobre o banco de sementes no solo (Caetano et al., 2001).

É preciso levar em consideração alguns aspectos quando da escolha do material mais indicado para o manejo das plantas espontâneas. $\mathrm{O}$ uso do plástico preto, para as condições de instalação deste pomar, tem alto custo, além de ser um material facilmente danificado pela ação do vento e de animais. Quanto à prática da capina, é uma operação onerosa, com dependência de mão de obra, além de poder causar danos ao sistema radicular das plantas de macieira. A acícula de pínus é material abundante na região onde foi executado este experimento, sendo facilmente coletada e aplicada ao pomar. O mesmo ocorre para a palha de capim-rabo-de-burro, que é uma planta que ocorre espontaneamente na região dos Campos de Cima da Serra, no Rio Grande do Sul, exigindo apenas corte da fitomassa.-

A resposta das plantas de macieira à cobertura do solo evidenciou variações entre os tratamentos aos 24 e aos 36 meses após o plantio (Tabela 1). A altura média de plantas aos 24 meses após o plantio foi de $1,37 \mathrm{~m}$ na testemunha, e de $1,74 \mathrm{~m}$ na cobertura com acículas de pínus. A altura de plantas aos 36 meses após o plantio variou entre os tratamentos, de $1,55 \mathrm{~m}$ na testemunha a 2,23 $\mathrm{m}$ na cobertura com plástico preto. Este tratamento não diferiu da cobertura com acículas de pínus $(2,07 \mathrm{~m})$ e do tratamento com capinas $(2,05 \mathrm{~m})$. Resposta semelhante foi verificada por Shribbs e Skroch (1986), onde maior altura de planta de macieira foi observada quando utilizado cobertura morta de Secale cereale (7,32m) e solo nu $(5,33 \mathrm{~m})$ em relação a outros tratamentos. O diâmetro do tronco, aos 24 meses após o plantio, foi menor na testemunha $(1,28 \mathrm{~cm})$ e atingiu $1,81 \mathrm{~cm}$ no tratamento com plástico preto, o qual foi superior aos manejos com aveia-preta + ervilhaca, roçada e testemunha, mas não diferiu dos demais tratamentos. O menor diâmetro do tronco, aos 36 meses, foi obtido na testemunha $(1,45 \mathrm{~cm})$, e o maior, com a cobertura de plástico preto $(3,23 \mathrm{~cm})$, que diferiu dos demais tratamentos, exceto da cobertura com acículas de pínus. Mervin e Stiles (1994) ao avaliarem diferentes sistemas de produção de macieiras durante seis anos, onde foram utilizadas coberturas vivas e mortas, aplicação de herbicidas e diferentes manejos do solo, verificaram que o incremento no diâmetro do tronco foi maior com a utilização de cobertura morta de palha de feno. Quanto à taxa de crescimento relativo do tronco das plantas, foi maior neste tratamento apenas no segundo ano de avaliação, sendo não significativo na maioria dos períodos avaliados.

Alguns estudos têm buscado a resposta das fruteiras de clima temperado ao manejo do solo, como reportado por Dal Bó e Becker (1994), em relação ao uso de plantas de cobertura de inverno em parreirais com 16 anos de idade. Neste caso, o cultivo de cobertura aumentou a produtividade de uva em relação ao solo capinado, possivelmente por melhorias no solo. Em outro experimento, o cultivo de leguminosas em pomares de ameixeira na região montanhosa da Índia resultou em decréscimo na pro- 
dução de frutas, em avaliação no sexto ano, quando comparado ao tratamento dessecado. Apesar disso, o manejo com plantas intercalares resultou em frutos maiores e mais pesados (Shilla \& Chauhan, 2004). Mais recentemente, verificou-se que o uso de plantas de cobertura de inverno beneficiou a produtividade e não teve efeito sobre o diâmetro do tronco de pessegueiro, em pomar conduzido no sistema de produção integrado, avaliado até o quarto ano de implantação (Rufato et al, 2007).

As avaliações do crescimento das plantas de macieira, realizadas aos 24 e aos 36 meses após o plantio, evidenciaram respostas negativas, tanto para altura quanto para diâmetro do tronco das macieiras, em função da cobertura do solo no período de crescimento (Figura 3). Isto aponta para o efeito de competição das plantas de cobertura do solo, que se tornou mais intensa e nítida em 2005/2006, como indicada pelo aumento nos coeficientes angulares e de determinação das equações. As plantas de cobertura do solo, sobretudo azevém, aveia-preta, aveia-preta + ervilhaca e aveia + nabo-forrageiro não cumpriram o objetivo de suprimir as plantas espontâneas, tendo desempenho equivalente à testemunha. No caso da roçada, que é uma prática consagrada e muito utilizada em pomares, seu efeito sobre a altura de plantas aos 24 meses, e diâmetro de plantas aos 24 e aos 36 meses, mostrou-se equivalente à testemunha. Tal resultado indica a ineficiência desta prática em reduzir a competição da vegetação espontânea com as plantas de macieira.

No caso da cultura da macieira, especialmente nas condições de cultivo orgânico na região Sul do Brasil, pouco se conhece sobre sua resposta ao manejo do solo. Outra questão a ser mais bem definida, e que poderia orientar melhor as práticas de cobertura do solo, é o período crítico de competição das plantas espontâneas, compreendido entre o início da floração até a colheita (Carvalho \& Vargas, 2004). Dessa forma, o manejo do solo nas áreas de produção frutícola deve ser orientado no sentido de oferecer cobertura permanente do solo, o que pode ser benéfico sob o aspecto ecológico (Fadini et al., 2001), mas evitando o excesso de crescimento das espécies intercalares, ou ainda manejando mais frequentemente a roçada, durante o período vegetativo e de frutificação do pomar. Salienta-se que os resultados aqui apresentados representaram o desenvolvimento da vegetação espontânea sem controle complementar durante o período de primavera-verão (outubro a fevereiro). Sugere-se, assim, continuidade das avaliações realizadas, incluindo roçadas adicionais ou rolagem das plantas de cobertura durante este período, de forma a reduzir a competição com a macieira.

TABELA 1 - Altura e diâmetro do tronco de plantas de macieiras aos 24 e aos 36 meses após o plantio, em resposta ao uso de diferentes coberturas do solo. Vacaria-RS (2006).

\begin{tabular}{lcccc}
\hline \multirow{2}{*}{ Tratamentos } & \multicolumn{2}{c}{ Altura de planta $(\mathbf{m})$} & \multicolumn{2}{c}{ Diâmetro de tronco (cm) } \\
\cline { 2 - 5 } Testemunha & $\mathbf{2 4}$ meses & $\mathbf{3 6}$ meses & $\mathbf{2 4}$ meses & $\mathbf{3 6}$ meses \\
Capina & $1,37 \mathrm{e}^{*}$ & $1,55 \mathrm{f}$ & $1,28 \mathrm{c}$ & $1,45 \mathrm{e}$ \\
Plástico preto & $1,47 \mathrm{cde}$ & $2,05 \mathrm{abc}$ & $1,41 \mathrm{abc}$ & $2,58 \mathrm{bc}$ \\
Sombrite & $1,66 \mathrm{ab}$ & $2,23 \mathrm{a}$ & $1,81 \mathrm{a}$ & $3,23 \mathrm{a}$ \\
Serragem de pínus & $1,55 \mathrm{~cd}$ & $1,79 \mathrm{de}$ & $1,52 \mathrm{abc}$ & $2,22 \mathrm{~cd}$ \\
Acícula de pínus & $1,56 \mathrm{bc}$ & $1,94 \mathrm{bcd}$ & $1,52 \mathrm{abc}$ & $2,68 \mathrm{bc}$ \\
Palha de capim-rabo-de-burro & $1,74 \mathrm{a}$ & $2,07 \mathrm{ab}$ & $1,75 \mathrm{ab}$ & $3,00 \mathrm{ab}$ \\
Azevém & $1,49 \mathrm{cde}$ & $1,87 \mathrm{bcde}$ & $1,44 \mathrm{abc}$ & $2,28 \mathrm{~cd}$ \\
Aveia-preta & $1,47 \mathrm{cde}$ & $1,77 \mathrm{def}$ & $1,41 \mathrm{abc}$ & $1,82 \mathrm{de}$ \\
Aveia-preta+ervilhaca & $1,45 \mathrm{cde}$ & $1,69 \mathrm{def}$ & $1,55 \mathrm{abc}$ & $1,90 \mathrm{de}$ \\
Aveia-preta+nabo & $1,39 \mathrm{de}$ & $1,71 \mathrm{def}$ & $1,27 \mathrm{c}$ & $1,95 \mathrm{de}$ \\
Azevém+trevo+nativas & $1,45 \mathrm{cde}$ & $1,68 \mathrm{ef}$ & $1,41 \mathrm{abc}$ & $1,73 \mathrm{de}$ \\
Roçada & $1,38 \mathrm{e}$ & $1,82 \mathrm{cde}$ & $1,44 \mathrm{abc}$ & $1,97 \mathrm{de}$ \\
\hline C.V. $(\%)$ & $1,45 \mathrm{cde}$ & $1,80 \mathrm{de}$ & $1,35 \mathrm{c}$ & $1,98 \mathrm{de}$ \\
\hline
\end{tabular}

*Médias seguidas da mesma letra nas colunas não diferem significativamente, pelo teste de Duncan $(P<0,05)$. 


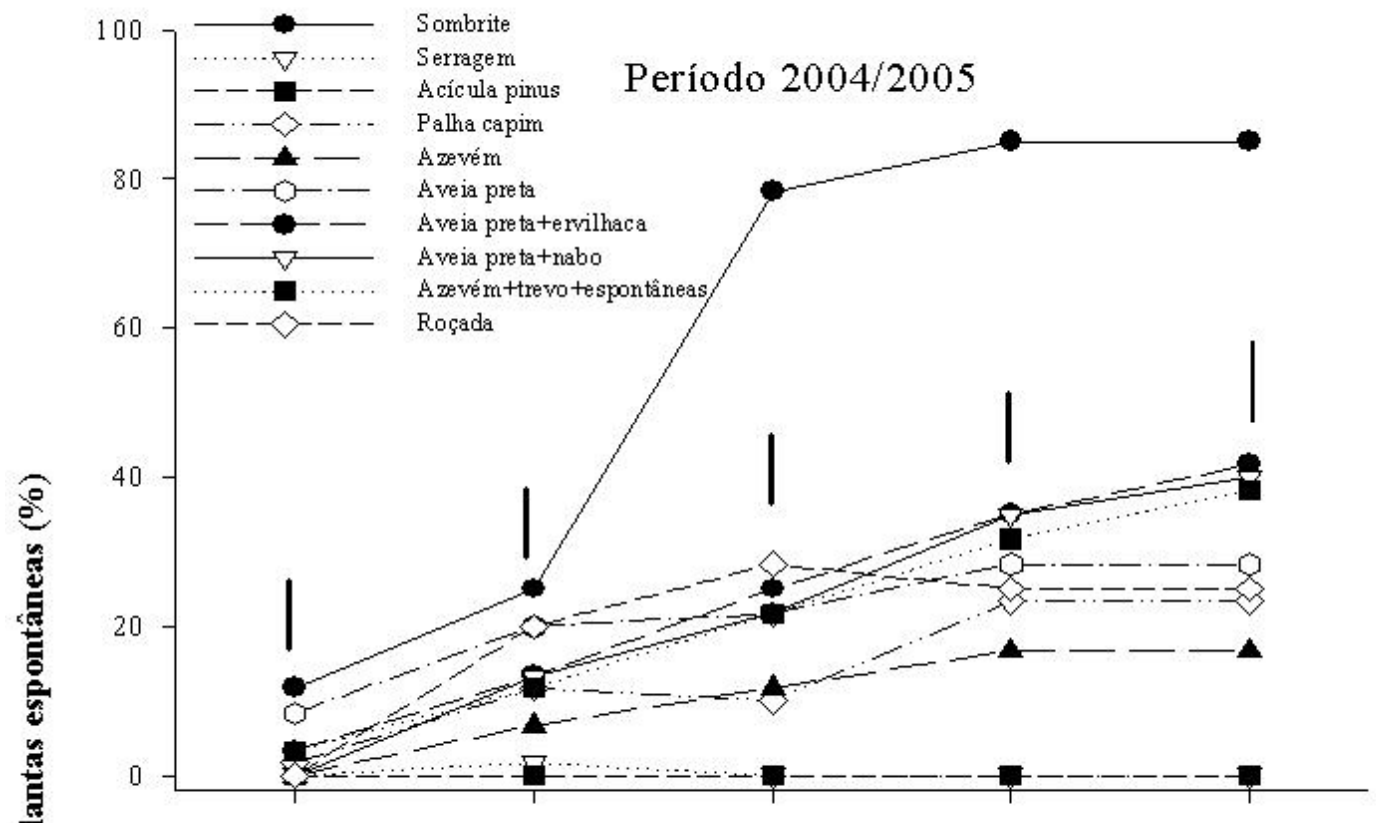

훙

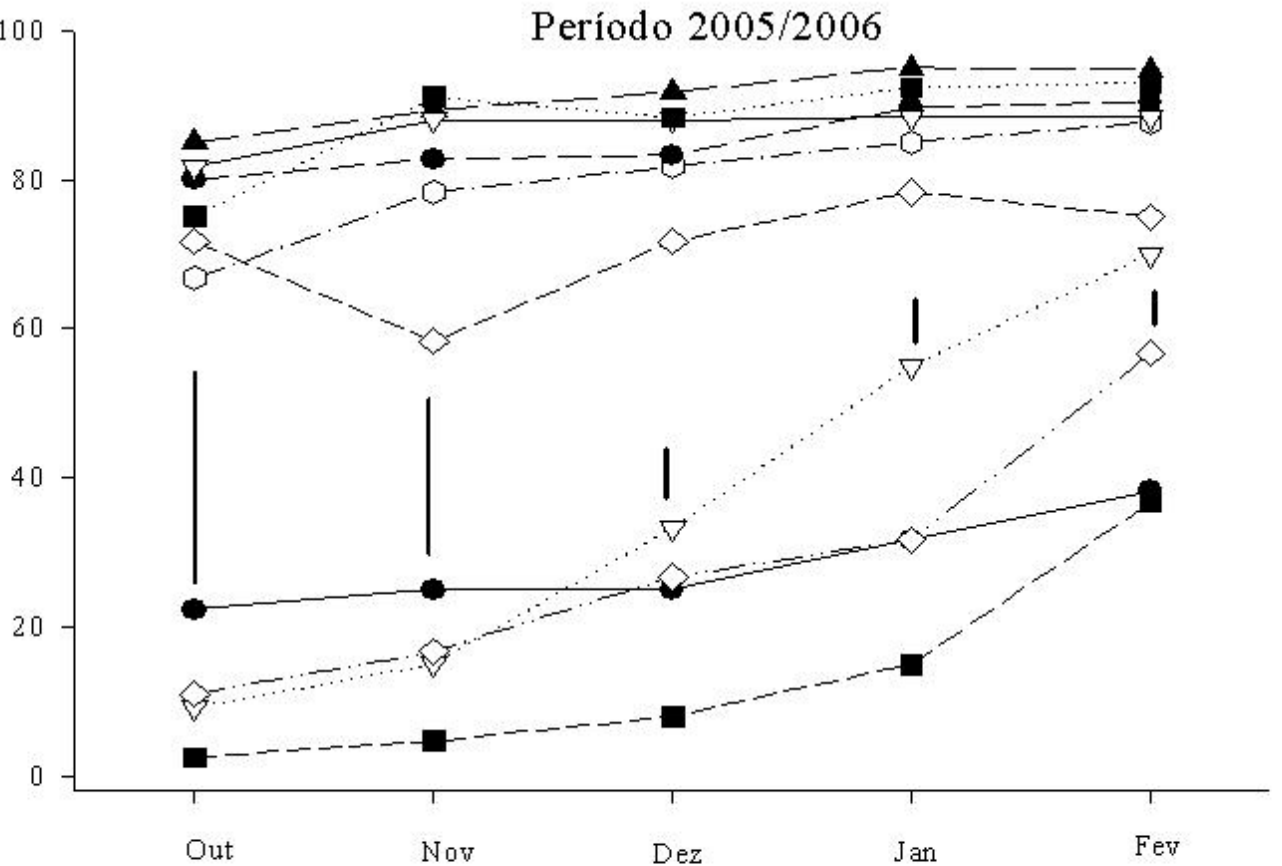

Épocas de avaliação

FIGURA 1 - Cobertura do solo pelas plantas espontâneas em resposta ao uso de diferentes materiais e manejos na linha de plantio da macieira, durante parte do período de crescimento, em 2004/2005 e 2005/2006. Barras verticais indicam diferenças mínimas significativas entre os tratamentos, em cada época de avaliação, calculadas pelo teste de Duncan, $(P<0,05)$. 


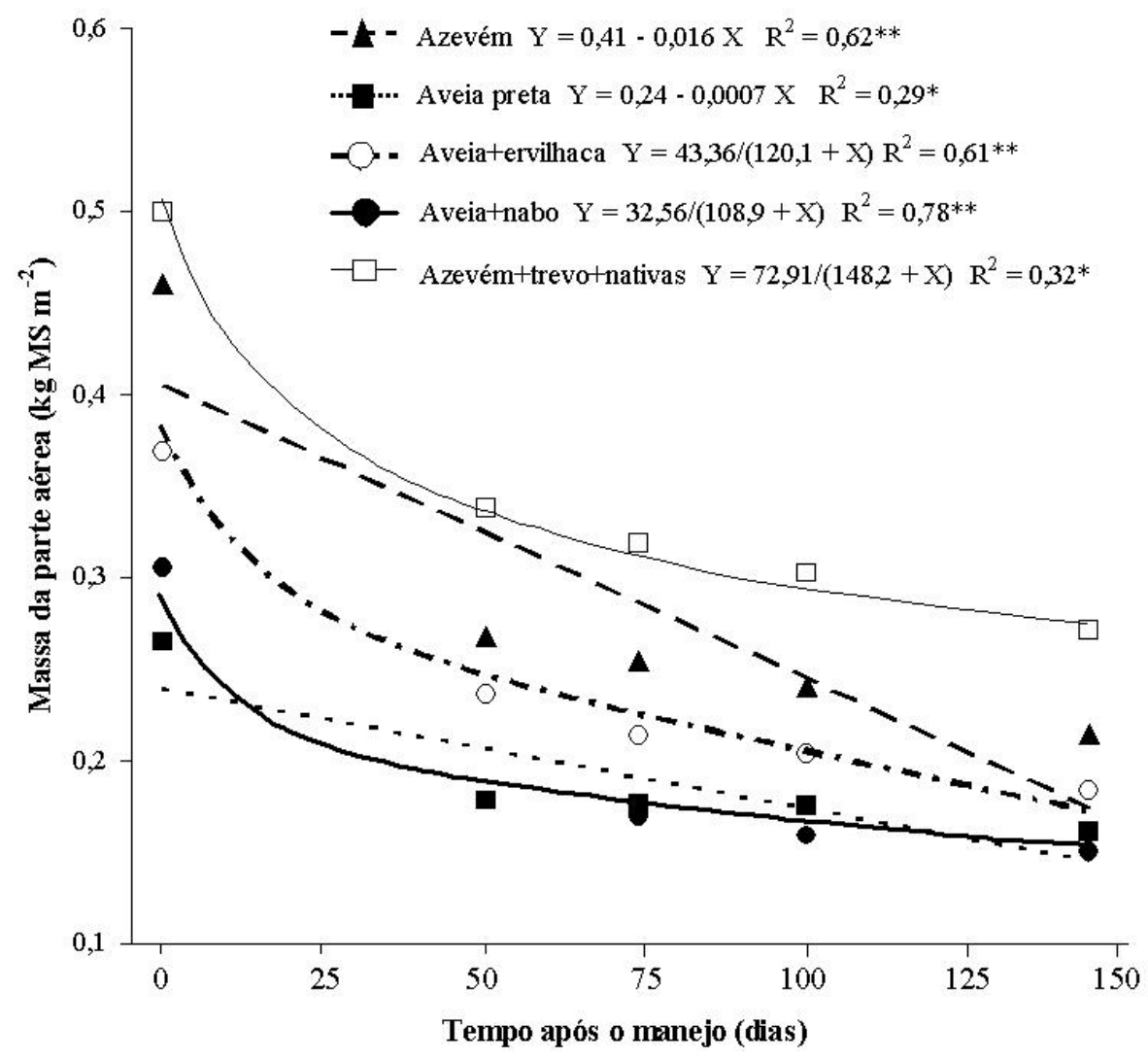

FIGURA 2 - Biomassa de matéria seca de plantas que permaneceram no solo, quantificada pela perda de biomassa durante o período de outubro de 2005 a fevereiro de 2006, na linha da cultura de macieiras ( $* \mathrm{e}^{* *}$, significativo a $P<0,05$ e $P<0,01$, respectivamente; $\mathrm{n}=15$ ). 

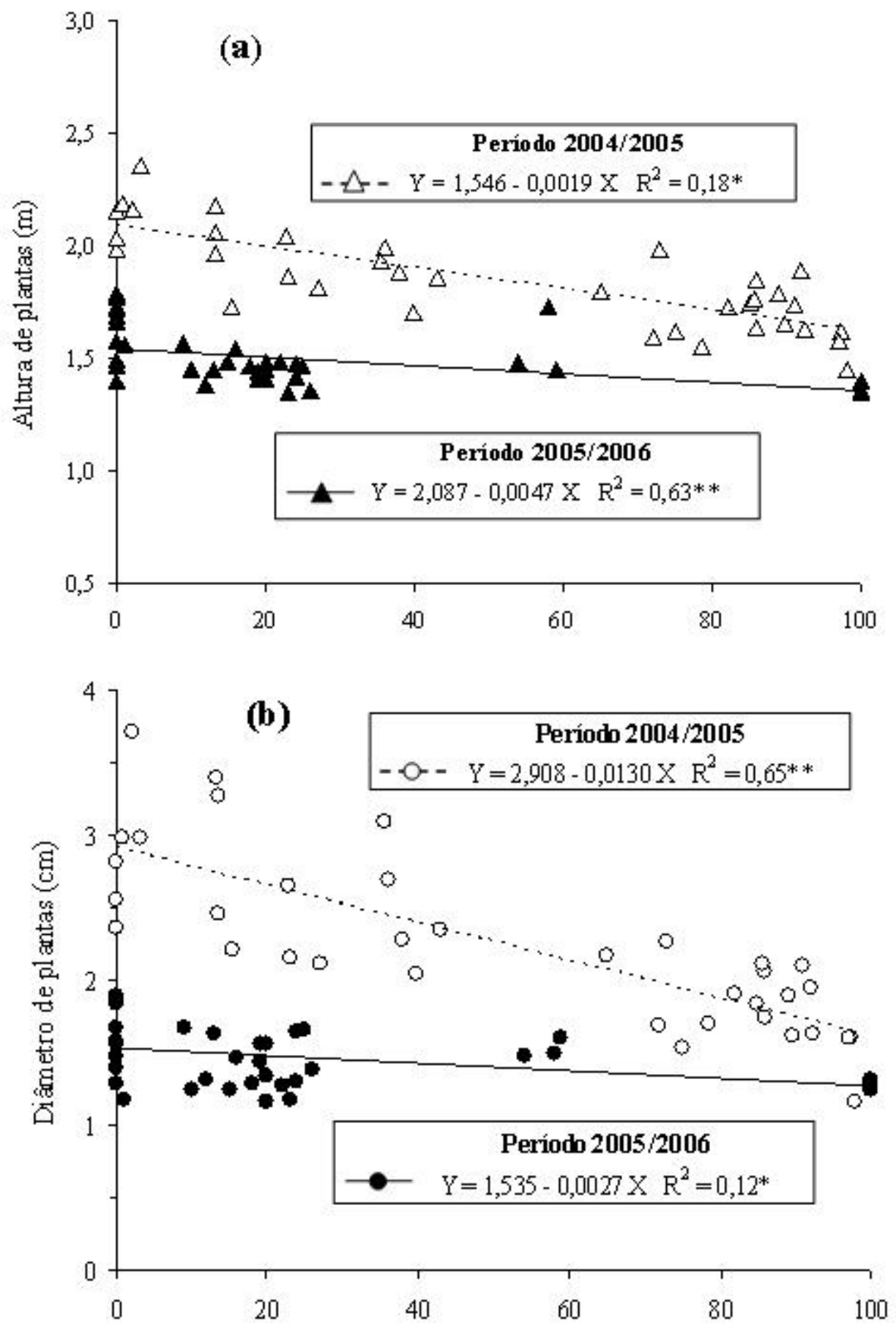

Cobertura do solo(\%)

FIGURA 3 - Relações entre cobertura do solo por plantas espontâneas e a altura de planta (a) e diâmetro do tronco (b) de macieira em resposta a diferentes materiais e manejos do solo na linha de plantio, nos períodos de crescimento de 2004/2005 e 2005/2006 (* e **, significativo a $P<0,05$ e $P<0,01$, respectivamente; $\mathrm{n}=39$ ). 


\section{CONCLUSÕES}

1-Os tratamentos mais eficientes na supressão da vegetação espontânea na linha de plantio da macieira, num pomar na fase de implantação, foram capina, plástico preto, acícula de pínus e palha de capim-rabo-de-burro.

2-A presença de vegetação espontânea na linha de plantio afeta o crescimento da macieira, com redução na altura e no diâmetro de plantas, evidenciando competição da vegetação de cobertura do solo no período de crescimento das macieiras.

\section{AGRADECIMENTOS}

À EMBRAPA/CNPUV - Unidade Experimental de Vacaria-RS, por ceder as instalações para a execução deste trabalho e pelo auxílio dos funcionários na condução dos trabalhos de campo.

\section{REFERÊNCIAS}

ALMEIDA, F. S. de. Efeitos alelopáticos de resíduos vegetais. Pesquisa Agropecuária Brasileira, Brasília, v. 26, n. 2, p. 221-236, 1991.

BALBINOT JÚNIOR, A.A.; BACKES, R.L.; TÔRRES, A.N.L. Desempenho de plantas invernais na produção de massa e cobertura do solo sob cultivos isolado e em consórcios. Revista de Ciências Agroveterinárias, Lages, v.2, n.2, p.113-117, 2003.

BRASIL, Ministério da Agricultura, Pecuária e Abastecimento. Instrução normativa 077/1999. Normas de produção, tipificação, processamento, envase, distribuição, identificação e de certificação da qualidade para os produtos orgânicos de origem vegetal e animal. Disponível em: $<$ http:// www.agricultura.gov.br>. Acesso em: 27 mar. 2008.

CAETANO, R.S.X.; CHRISTOFFOLETI, P.J.; VICTORIA FILHO, R. "Banco" de sementes de plantas daninhas em pomar de laranjeira 'Pera'. Scientia Agricola, Piracicaba, v.58, n.3, p.509-517, 2001.

CARVALHO, J.E.B. de; VARGAS, L. Manejo e controle de plantas daninhas em frutíferas. In: VARGAS, L.; ROMAN, E. S. Manual de manejo e controle de plantas daninhas. Bento Gonçalves: EMBRAPA/ CNPUV, 2004. p.481-517.

COMISSÃO DE QUÍMICA E FERTILIDADE DO SOLO - RS/SC. Sociedade Brasileira de Ciência do Solo. Núcleo Regional Sul. Manual de adubação e de calagem para os Estados do Rio Grande do Sul e de Santa Catarina. 10. ed. Porto Alegre, 2004. 400 p.

DAL BÓ, M.A.; BECKER, M. Avaliação de sistemas de manejo do solo para a cultura da uva. Pesquisa Agropecuária Brasileira, Brasília, v.29, n.2, p.263266, 1994.

ERASMO, E.A.L.; AZEVEDO, W.R.; SARMENTO, R.A.; CUNHA, A.M.; GARCIA, S.L.R. Potencial de espécies utilizadas como adubos verde no manejo integrado de plantas daninhas. Planta Daninha, Viçosa, v.22, n.3, p.337-342, 2004.

FADINI, L.A.M.; REGINA, M.A.; FRÁGUAS, J.C.; LOUZADA, J.N.C. Efeito da cobertura vegetal sobre a abundância e diversidade de inimigos naturais de pragas em vinhedos. Revista Brasileira de Fruticultura, Jaboticabal, v.23, n.3, p.573-576, 2001.

GOH, K.M.; PEARSON, D.R.; DALY, M.J. Effects of apple orchard production systems on some important soil physical, chemical and biological quality parameters. Biological Agriculture and Horticulture, Bicester, v.18, n.3, p.269-292, 2000.

MATHEIS, H.A.S.M.; AZEVEDO, F. A.; VICTORIA FILHO, R. Adubação verde no manejo de plantas daninhas na cultura de citros. Laranja, Cordeirópolis, v.27, n.1, p.101-110, 2006.

MEDEIROS, A.R.M. de. Leguminosas de inverno: uma opção no manejo do solo em pomares de fruteiras de clima temperado. Hortisul, Pelotas, v.2, n.1, p.14-15, 1992.

MEDEIROS, A.R.M. de; SANTOS, A.M. Práticas culturais. In: MEDEIROS, A.R.M. de; SANTOS, A.M. Morango: produção. Pelotas: Embrapa Clima Temperado, 2003. p. 53-56. (Frutas do Brasil, 40)

MERVIN, I. A.; STILES, W. C. Orchard groundcover management impacts on apple tree growth and yeld and nutrient availability and uptake. Journal of the American Society for Horticultural Science, Alexandria, v.119, n.2, p.209-215, 1994.

MORENO, J.A. Clima do Rio Grande do Sul. Porto Alegre: Secretaria da Agricultura, 1961. 30p.

NEVES, C.S.V.J.; FELLER, C.; KOUAKOUA, E. Efeito do manejo do solo e da matéria orgânica solúvel em água quente na estabilidade de agregados de 
um latossolo argiloso. Ciência Rural, Santa Maria, v.36, n.5, p.1410-1415, 2006.

RAGOZO, C.R.A.; LEONEL, S.; CROCCI, A.J. Adubação verde em pomar cítrico. Revista Brasileira de Fruticultura, Jaboticabal, v.28, n.1, p.69-72, 2006.

RUFATO, L.; DE ROSSI, A.; KRETZSCHMAR, A.A.; PICOLOTTO, L.; FACHINELLO, J.C. Coberturas vegetais no desenvolvimento vegetativo de plantas de pessegueiro. Revista Brasileira de Fruticultura, Jaboticabal, v.29, n.1, p.107-109, 2007.

SHYLLA, B.; CHAUHAN, J.S. Influence of orchard floor management practices on cropping and quality of Santa Rosa plum grown under mid hill conditions. Acta Horticulturae, Leuven, n.662, p.213-216, 2004.
SHRIBBS, J.M.; SKROCH, W.A. Influence of 12 ground cover systems on young (cultivar) Smoothee Golden Delicious apple (Malus domestica) trees: I. Growth. Journal of the American Society for Horticultural Science, Alexandria, v.111, n.4, p.525-528, 1986.

WALSH, B.D.; SALMINS, S.; BUSZARD, D.J.; MACKENZIE, A.F. Impact of soil management systems on organic dwarf apple orchards and soil aggregate stability, bulk density, temperature and water content. Canadian Journal of Soil Science, Ottawa, v.76, n.2, p.203-209, 1996.

WILLIAMS, S.T.; GRAY, T.R.G. Decomposition of litter on soil surface. In: DICKINSON, C.H.; PUGH, G.J.F. (Ed.). Biology of plant litter decomposition. London: Academic Press, 1977. v.1, 241 p. 